\title{
ASO Author Reflections: Lymphovascular Invasion has a Similar Prognostic Value as Lymph Node Involvement in Patients with Early Gastric Cancer
}

\author{
Seohee Choi, $\mathrm{MD}^{1,2}$, and Woo Jin Hyung, $\mathrm{MD}^{1,2}$ (D) \\ ${ }^{1}$ Department of Surgery, Yonsei University College of Medicine, Seoul, Republic of Korea; ${ }^{2}$ Gastric Cancer Center, \\ Yonsei Cancer Center, Yonsei University Health System, Seoul, Republic of Korea
}

\section{PAST}

Lymphovascular invasion (LVI) was known as a poor prognosticator for gastric cancer patients without lymph node (LN) involvement; however, there was no consensus as to whether LVI affects long-term survival in patients with early gastric cancer regardless of lymph node (LN) involvement. ${ }^{1}$ In addition, previous studies have demonstrated the prognostic values of LVI in relation to early gastric cancer in a small number of patients. ${ }^{2}$

\section{PRESENT}

We evaluated the prognostic significance of LVI on recurrence and long-term survival in early gastric cancer patients who underwent gastrectomy, by comparing the groups after stratifying by LVI and LN status. The study demonstrated that early gastric cancer patients with LVI had a poor prognosis even without LN involvement, similar to early gastric cancer with $\mathrm{LN}$ involvement. ${ }^{3}$ Moreover, patients with LVI showed a high recurrence rate and hematogenous metastases as the most common pattern of recurrence.

\section{FUTURE}

Among early gastric cancer patients, LVI should be used to identify those patients with a high risk of recurrence and a poor prognosis. Because this specific group of early gastric cancer patients with LVI had a poor prognosis, they require intensive follow-up. Based on the above findings, LVI status should be informed to early gastric cancer patients for a more accurate prognosis.

DISCLOSURE Woo Jin Hyung reports receiving research Grants from Medtronic and GC Pharma. He is the Chief Executive Officer of Hutom and holds stocks in the company. He has also provided consultancy services to Ethicon and Verb Surgical outside the submitted work, and has received lecture fees from Stryker. Seohee Choi reports no conflicts of interest.

\section{REFERENCES}

1. Lee JH, Kim MG, Jung MS, Kwon SJ. Prognostic significance of lymphovascular invasion in node-negative gastric cancer. World $J$ Surg. 2015;39:732-9.

2. Liu C, Zhang R, Lu Y, et al. Prognostic role of lymphatic vessel invasion in early gastric cancer: a retrospective study of 188 cases. Surg Oncol. 2010;19:4-10.

3. Choi S, Song JH, Lee S, et al. Lymphovascular invasion: traditional but vital and sensible prognostic factor in early gastric cancer. Ann Surg Oncol. 2021. https://doi.org/10.1245/s10434-02 1-10224-6.

Publisher's Note Springer Nature remains neutral with regard to jurisdictional claims in published maps and institutional affiliations.

(C) Society of Surgical Oncology 2021

First Received: 25 May 2021

Accepted: 25 May 2021;

Published Online: 9 June 2021

W. J. Hyung, MD

e-mail: wjhyung@yuhs.ac 